\title{
Blockchain Technology and Its Potential Effects on Accounting: A Systematic Literature Review
}

\author{
Asuman Atik ${ }^{1} \odot$, Göksal Selahatdin Kelten² $\odot$
}

\begin{abstract}
With the growth of the business world, autonomous software programs such as MRP, ERP, and SAP have been used to synchronize different units and departments since the 1960s. There have been great technological developments in the last decades, such as Blockchain, the Internet of Things, artificial intelligence, and machine learning. The attention of the accounting world has also been on those technological developments, especially on Blockchain Technology. Accounting academics and professionals have been trying to understand how blockchain technology can affect accounting and what kind of changes might be brought about by that technology. Therefore, the purpose of this study is to make a systematic literature review in order to foresee the potential effects of blockchain on accounting. Selected keywords were searched for on the Scopus database. The results show that most of the studies in this area focus on technical issues and the development of software applications, and a small number of studies make a connection between blockchain and accounting. Although most of the authors are very optimistic about blockchain technology and claim that this technology may change the double-entry accounting system completely and radically, some have discrete approach and express critical views.
\end{abstract}

Keywords

Blockchain, Cryptocurrency, Accounting, Auditing

\section{Introduction}

There are many important milestones in mankind's history. The invention of writing, the industrial revolution, the development of firearms, and geographical explorations are examples of these milestones. The discovery of money also has great importance because it provides a standard measurement of value and it is very difficult to make trade between parties without it. The invention of the Internet also has had a considerable impact on the development of international trade as well as the increase in usage of money in daily life. Furthermore, there have been notable developments in the field of technology in the last century. The widespread use of the Internet has brought digitalization to almost every field. Especially e-commerce

1 Corresponding Author: Asuman Atik (Assoc. Prof.), Marmara University, Faculty of Business Administration, Department of Accounting and Finance, Istanbul, Turkey. E-mail: aatik@marmara.edu.tr ORCID: 0000-0001-7727-4585

2 Göksal Selahatdin Kelten (Res. Asst.), Pamukkale University, Faculty of Economics and Administrative Sciences, Department of Accounting and Finance, Denizli, Turkey. E-mail: gkelten@pau.edu.tr ORCID: 0000-0002-7273-7613

To cite this article: Atik, A., \& Kelten, G. S. (2021). Blockchain Technology and Its Potential Effects on Accounting: A Systematic Literature Review. Istanbul Business Research, 50(2), 495-515. http://doi.org/10.26650/ibr.2021.50.806870 
has reached huge volumes and very large-scaled global shopping sites have appeared like Amazon, Alibaba, eBay, and Walmart. The digitalization that started with the Internet has increased the economic interaction between countries and the world is globally integrated by eliminating the borders in the economic sense.

Due to the digitalization and globalization in the world, new developments, new rules, and new problems have arisen in the areas of accounting, finance, payment systems, fund transfers, storage, and the transfer of data. Blockchain Technology (BCT) and cryptocurrency 1 are two of the most important developments over the last decade. After Nakamoto's (2008) "Bitcoin: A peer-to-peer electronic cash system" article, BCT and cryptocurrencies gained prevalence. Nakamoto (2008) states that the existence of the trusted party in the electronic payment systems is increasing the cost of money transfers from one to another. Therefore, there is a need for a payment system that enables individuals to transfer money between two parties without a third party. To meet this need, an electronic system was developed, which is "peer-to-peer" and based on cryptology, which allows transacting directly with each other. Blockchain has been embedded in a lot of areas, particularly, the digital platforms based on BCT have been developed and submitted to the banking sector and financial industries. "Stella" is a joint project of the European Central Bank and the Bank of Japan. They have been working on assessing the applicability of Distributed Ledger Technology (DLT) solutions in financial market infrastructures since 2016 and they report the aim of "Stella" as "to contribute to the ongoing broader debate around the potential usability of DLT while not being geared towards replacing existing central bank services with DLT-based solutions" (European Central Bank and Bank of Japan, 2018).

Accounting professionals and academics cannot stand unresponsive to the development of the $\mathrm{BCT}$ and have been searching for possible usage areas of this technology in accounting. Big accounting firms have started to develop software applications based on BCT and to promote the usage of blockchain. New debates have arisen on the accounting of cryptocurrencies and the requirement for new IFRSs, which will conform to BCT.

This study aims to make a systematic literature review to understand the potential effects of $\mathrm{BCT}$ on accounting and make some inferences for the future of the accounting profession. In order to increase the understandability of the research topic, blockchain and cryptocurrency concepts are explained in the following part. The research methodology of this study is explained in the third part. The fourth part summarizes the related literature, and the fifth part is the conclusion.

1 The terms "cryptocurrency" and "virtual currency" are often used interchangeably. In this paper, we only used "cryptocurrency" to avoid confusions. 


\section{Cryptocurrency and Blockchain Technology}

Human beings used to barter under primitive conditions. When life became more complex and bartering was not sufficient, it became necessary to fix a particular commodity as a "medium of exchange and a measure of value". This intermediate commodity which is called "money" has appeared in many different forms such as cattle, iron, salt, shells, dried cod, tobacco, sugar, nails, stone, etc. in different times and places (Innes, 1913; Keynes, 1915). Historical records show that leather money was in usage in China approximately 100 B.C. and again the first money which was made from paper also emerged in China in 806 (Central Bank of the Republic of Turkey, 2018) In short, everything can be used as "money" if it has the following three attributions: "mediating to an exchange", "being used as the unit of account" and "a storage of value" (Asmundson and Oner, 2012; Yermack, 2013).

Cryptocurrency is defined as "a digital representation of value that can be digitally traded and functions as (1) a medium of exchange; and/or (2) a unit of account; and/or (3) a store of value, but does not have legal tender status in any jurisdiction" by Financial Action Task Force in 2014. In other words, cryptocurrencies are neither issued by a central bank nor controlled by a public authority as shown in Table 1, but they represent a value and have been used as an instrument of payment since the beginning of 2009 and have been traded digitally (European Banking Authority, 2014).

Table 1

A Money Matrix

\begin{tabular}{lccc}
\cline { 3 - 4 } & & \multicolumn{2}{c}{ Form of the Money } \\
\cline { 3 - 4 } Legality & Regulated & Physical & Digital \\
\cline { 3 - 4 } & Unregulated & Certain Types of Local Currencies & E-Money \\
& &
\end{tabular}

Source: European Central Bank, 2012

Cryptocurrencies are generally under the control of their developers and used as "real" money within the members of a specific group. There are three types of schemes as follows: "closed schemes", "unidirectional schemes" and "bidirectional schemes". The closed schemes are generally used in online games. There is only one type (in/out), which flows in a unidirectional scheme. The third type of scheme allows cryptocurrencies to act just like fiat money by setting a buy and sell rate (European Central Bank, 2012). The first cryptocurrency appeared in 2009 in the name of Bitcoin. "Bitcoins are digital coins which are not issued by any government, bank, or organization, and rely on cryptographic protocols and a distributed network of users to mint, store, and transfer" (Ron and Shamir, 2013: 6). Since then, lots of cryptocurrencies have been launched in the financial markets. There are 5,903 cryptocurren$\operatorname{cies}^{2}$ in the world as of June 2021, and Bitcoin has the largest market share. Countries have

2 https://www.investing.com/crypto/currencies (Investing.com, 26.06.2021) 
different approaches on cryptocurrencies. Generally, cryptocurrencies are evaluated from tax and illegal acts perspectives. While some countries have forbidden the usage of cryptocurrencies, some others accepted them as a legal payment tool (Y1ldırım, 2019). ${ }^{3}$

It is not possible to think of trading activities without recording the transactions, so ledger accounts have been used for record-keeping since ancient times. However, their shapes have evolved from tablets to papyrus, parchment to papers, and bytes over time. A new era has started in the ledger accounts with cryptocurrencies and the algorithmic software DLT has been developed in the last decade (Walport, 2015). Because DLT has been implemented in a variety of industries, it does not have a common single definition. The meaning of DLT differs according to the usage area (Mills et al., 2017). Even if the definitions of DLT are different from each other, the "peer-to-peer network system" and "decentralized" or "distributed" terms are fixed parts of all definitions. Another term that has the same meaning as DLT is "blockchain". "Blockchain is the ledger (book of records) of all transactions, grouped in blocks, made with a (decentralized) virtual currency scheme” (European Central Bank, 2015). Blockchain or DLT is a kind of database which is based on a "peer-to-peer" network philosophy and it makes the records non-deletable forever (Swanson, 2015) and it is possible to keep records by many people or organizations and no one is superior or inferior to others (Kornfeld et al., 2016).

Blockchain is the combination of blocks that can include a large number of transaction data and follow each other. Each block has a hash value. The first block is called a Genesis block and because there is no block before it, its hash value is zero. Each block contains the previous block's hash code to keep the connectivity of the blocks (Bamakan et al., 2020).

Members who want to participate in a particular blockchain use nodes (computer devices), which are connected. When one member creates a block, other nodes have the right to accept or reject it. Members should also make an agreement related to the rights of participants in the blockchain. These agreements are called "consensus algorithms". The blockchain consensus algorithms developed till now are Proof of Work, Proof of Stake, Delegated Proof of Stake, Proof of Elapsed Time, Practical Byzantine Fault Tolerance, Delegated Byzantine Fault Tolerance, Proof of Weight, Proof of Burn, Proof of Capacity, Proof of Importance, Proof of Activity, and Directed Acyclic Graphs. They differ according to their decentralization and security levels, energy consumptions, degree of difficulty, and participation level of nodes (Bamakan et al., 2020; Yu et al., 2020).

According to accessibility and controllability by the network members, there are three categories of blockchain: (1) a public blockchain can be accessed, shared, and controlled by

3 The usage of crypto assets as a means of payment has been prohibited in Turkey with a regulation announced in the Official Newspaper published on 16 th of April, 2021, (https://www.resmigazete.gov.tr/eskiler/2021/04/20210416-4. htm). 
all the members, (2) in a private blockchain, the access can be with the permission of a third party and it is centralized to some extent, and (3) a consortium blockchain is governed by several institutions all of which directly participate in the consensus protocol (Ali et al., 2020; Salimitari et al., 2020).

The intermediary functions or the third parties have disappeared with the blockchain. Blockchain uses a decentralized ledger, so that, it enables each user to copy all records onto their computers. However, it is not possible in the existing system which allows only trusted parties to hold all transaction records, especially in bank accounts. Because the BCT makes the transactions immutable and reduces anonymity, government services may also adopt BCT to increase transparency and accountability (Boucher et al., 2017).

One of the concepts that cannot be separated from the blockchain, especially when we look through an accounting perspective, is the Internet of Things (IoT). "The Internet of Things (IoT) is set to ubiquitously connect a huge number of devices (embedded with sensors and actuators) to the Internet, digitizing the physical world into computer-based data systems" (Wang et al., 2019: 1). "Built-in blockchain" and "Blockchain as a service" are the two types of blockchain for IoT. In the first one, IoT devices are built-in, which means all IoT devices can operate as blockchain nodes and become part of a blockchain network. In the second one, the data collected by an IoT device is entered into the blockchain by a user (Wang et al., 2019).

Although most of the studies focus on the blockchain usage as a means of cryptocurrency transfer, this technology can also be used for non-financial activities, such as supply chain management, voting in elections, healthcare records management, identity management systems, access control systems, decentralized notary and tourism organizations (Boucher et al., 2017; Maesa and Mori, 2020; Rashideh, 2020).

Some researchers suggest different types of blockchains. For example, Back et al. (2014) propose "pegged sidechains", which allow the transfer of coins between multiple blockchains and makes interoperation with each other easier. Wang and Kogan (2018) take a step further and propose a framework design for a blockchain-based transaction processing system for the implementation of blockchain for accounting and auditing fields. They assume a blockchain-based enterprise and represent its assets and resources with different tokens and different side chains. Every digital coin in the blockchain is a token. Vincent et al. (2020) design a blockchain that enables auditors to participate in the client's blockchains and use them in audit processes. Lafourcade and Lombard-Platet (2020) go even further and test the interoperability of two blockchains.

There are also some studies mentioning the drawbacks of blockchain, such as execution and storage costs, energy consumption, global warming, and cybercrime problems. Blockchain systems are expensive and consume a huge level of electricity. Additionally, because 
countries have not made laws related to bitcoin and blockchain, when there is fraud, cybercrime, terrorist financing, or any conflict between the parties, it is not clear how to solve these problems (Chang et al., 2020).

\section{The Research Methodology of the Study}

Bitcoin and blockchain, which occupy an important place in the world's agenda, are mentioned in the article of Nakamoto for the first time in 2008. There are hundreds of studies that have been carried out on Blockchain, Distributed Ledger Technology (DLT), and cryptocurrencies since 2008 in literature. Therefore, this study systematically reviews the academic studies published between 2008 and 2021.

A systematic review is a specific technique which reviews all of the existing articles related to a specific research topic and evaluates the data, analyses, and contributions of articles, and synthezes them to report a conclusion on what is known and what is unknown about the topic (Denyer and Tranfield, 2009). It tries to find out what literature inspires the practice of and reveals what is unknown to give a lead for future studies (Grant and Booth, 2009). There are six key phases in the systematic review as follows: "mapping the field through a scoping review"; "comprehensive search"; "quality assessment"; "data extraction"; "synthesis"; and the last stage is "write up" (Jesson et al., 2011: 108).

After determining the coverage period as 2008-2021, databases and keywords were selected. In this manner, the keywords: "blockchain and accounting", "cryptocurrency and accounting", "distributed ledgers and accounting", "smart contract and accounting" and "virtual currency and accounting" were searched for on the Scopus database. The categorization of the found studies according to their disciplines is presented in Table 2.

When "blockchain and accounting" was searched, 285 different studies were found. When the search was repeated with different keywords, such as "cryptocurrency and accounting" or "virtual currency and accounting", the results included the same studies obtained with other searches. By using the "save the selected documents to list" feature of Scopus, the results of all keyword searches were integrated, and 334 different studies were listed. 108 of those 334 studies were in the "Business, Management and Accounting" discipline, and we focused more on them. 
Table 2

The Disciplines of the 334 studies listed by Scopus

\begin{tabular}{lc}
\hline Subject area & \# of studies \\
\hline Business, Management and Accounting & 108 \\
Computer Science & 192 \\
Economics, Econometrics and Finance & 52 \\
Engineering & 90 \\
Decision Sciences & 57 \\
Social Sciences & 40 \\
Mathematics & 52 \\
Energy & 32 \\
Arts and Humanities & 5 \\
Biochemistry, Genetics and Molecular Biology & 5 \\
Materials Science & 15 \\
Multidisciplinary & 3 \\
Medicine & 7 \\
Physics and Astronomy & 19 \\
Agricultural and Biological Sciences & 3 \\
Environmental Science & 11 \\
Immunology and Microbiology & 1 \\
Chemical Engineering & 1 \\
Earth and Planetary Sciences & 1 \\
Chemistry & 2 \\
Psychology & 299 \\
Pharmacology, Toxicology and Pharmaceutics & 1 \\
Total & 2 \\
\hline Sourc: Scops & 3 \\
\hline
\end{tabular}

Source: Scopus

Because one study can be categorized under different disciplines, the total number of the studies from different disciplines increased to 699.

Table 3 shows the number of studies categorized under different disciplines. As mentioned before, the total number of different studies in "Business, Management and Accounting" discipline is 108 , however because one study can be found with other keyword searches, the total number of the studies from different keyword searches increased to 161. 
Table 3

Number of Studies Categorized according to Disciplines with Different Keyword Search

\begin{tabular}{|c|c|c|c|c|c|c|}
\hline Subject area & $\begin{array}{c}\text { block- } \\
\text { chain } \\
\text { and } \\
\text { account- } \\
\text { ing } \\
\end{array}$ & $\begin{array}{l}\text { crypto- } \\
\text { currency } \\
\text { and } \\
\text { account- } \\
\text { ing } \\
\end{array}$ & $\begin{array}{c}\text { distrib- } \\
\text { uted } \\
\text { ledgers } \\
\text { and ac- } \\
\text { counting }\end{array}$ & $\begin{array}{c}\text { smart } \\
\text { contract } \\
\text { and } \\
\text { account- } \\
\text { ing } \\
\end{array}$ & $\begin{array}{l}\text { virtual } \\
\text { curren- } \\
\text { cy and } \\
\text { account- } \\
\text { ing } \\
\end{array}$ & $\begin{array}{l}\text { To- } \\
\text { tal }\end{array}$ \\
\hline $\begin{array}{l}\text { Business, Management and } \\
\text { Accounting }\end{array}$ & 92 & 18 & 25 & 20 & 6 & 161 \\
\hline Computer Science & 172 & 19 & 34 & 43 & 5 & 273 \\
\hline $\begin{array}{l}\text { Economics, Econometrics and } \\
\text { Finance }\end{array}$ & 37 & 17 & 11 & 6 & 5 & 76 \\
\hline Engineering & 84 & 6 & 17 & 22 & 2 & 131 \\
\hline Decision Sciences & 54 & 4 & 11 & 7 & 3 & 79 \\
\hline Social Sciences & 32 & 9 & 5 & 4 & 2 & 52 \\
\hline Mathematics & 43 & 7 & 6 & 19 & 1 & 76 \\
\hline Energy & 27 & 2 & 8 & 7 & 1 & 45 \\
\hline Arts and Humanities & 4 & 1 & 1 & 0 & 0 & 6 \\
\hline $\begin{array}{l}\text { Biochemistry, Genetics and } \\
\text { Molecular Biology }\end{array}$ & 4 & 1 & 0 & 1 & 0 & 6 \\
\hline Materials Science & 13 & 1 & 2 & 2 & 0 & 18 \\
\hline Multidisciplinary & 2 & 3 & 0 & 0 & 0 & 5 \\
\hline Medicine & 6 & 1 & 0 & 4 & 1 & 12 \\
\hline Physics and Astronomy & 17 & 3 & 5 & 3 & 0 & 28 \\
\hline $\begin{array}{l}\text { Agricultural and Biological } \\
\text { Sciences }\end{array}$ & 2 & 1 & 1 & 0 & 0 & 4 \\
\hline Environmental Science & 11 & 0 & 3 & 0 & 1 & 15 \\
\hline Immunology and Microbiology & 1 & 0 & 0 & 0 & 0 & 1 \\
\hline Chemical Engineering & 2 & 0 & 0 & 0 & 0 & 2 \\
\hline Earth and Planetary Sciences & 1 & 0 & 1 & 0 & 0 & 2 \\
\hline Chemistry & 2 & 0 & 1 & 0 & 0 & 3 \\
\hline Psychology & 0 & 1 & 0 & 0 & 0 & 1 \\
\hline $\begin{array}{l}\text { Pharmacology, Toxicology and } \\
\text { Pharmaceutics }\end{array}$ & 1 & 1 & 1 & 0 & 0 & 3 \\
\hline Total & 607 & 95 & 132 & 138 & 27 & 999 \\
\hline
\end{tabular}

Source: Scopus

The following figure shows trend of studies by year. The number of studies has started to increase since 2016. However when we examine the percentages presented in Figure 2, we see that only $44 \%$ of the studies are articles published in journals and $43.7 \%$ are conference papers. 
Documents by year

Scopus

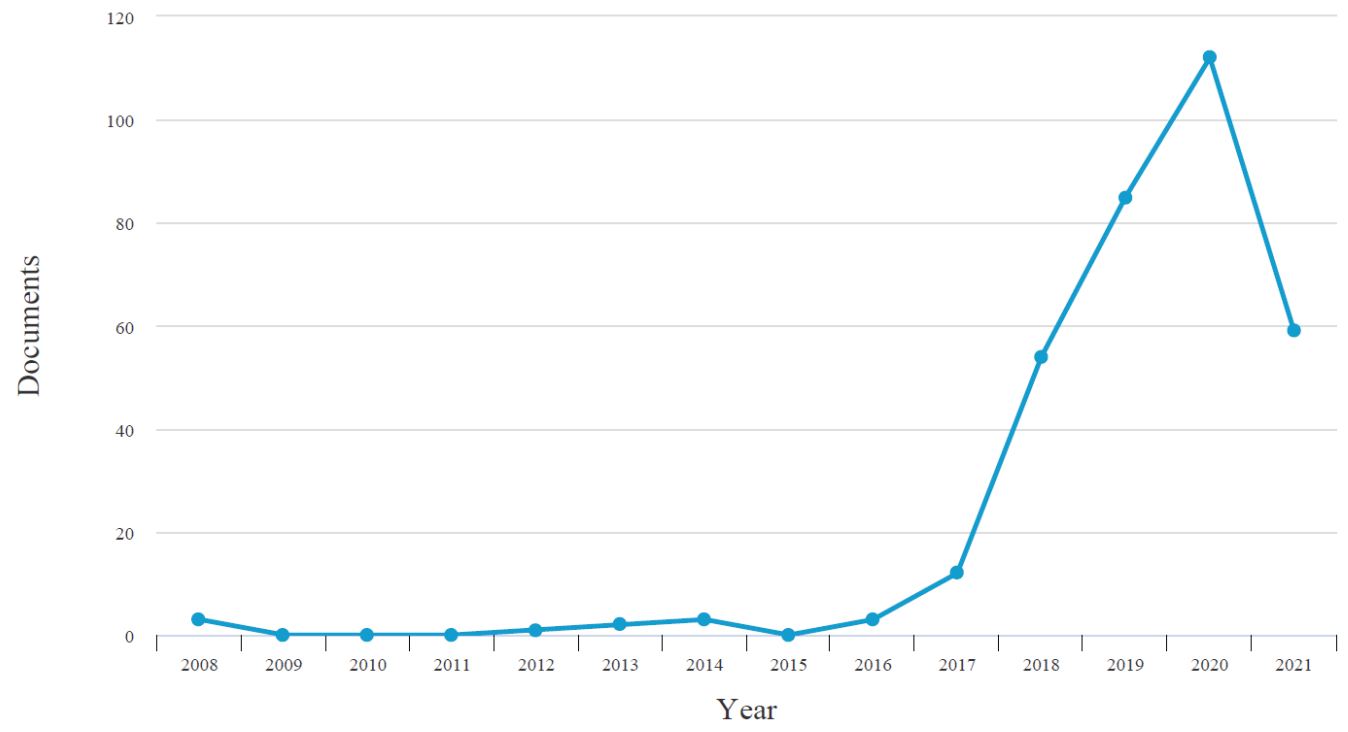

Copyright $\odot 2021$ Elsevier B.V. All rights reserved. Scopus@ is a registered trademark of Elsevier B.V.

Figure 1. Search Results by the Year

Source: Scopus

Documents by type

Scopus

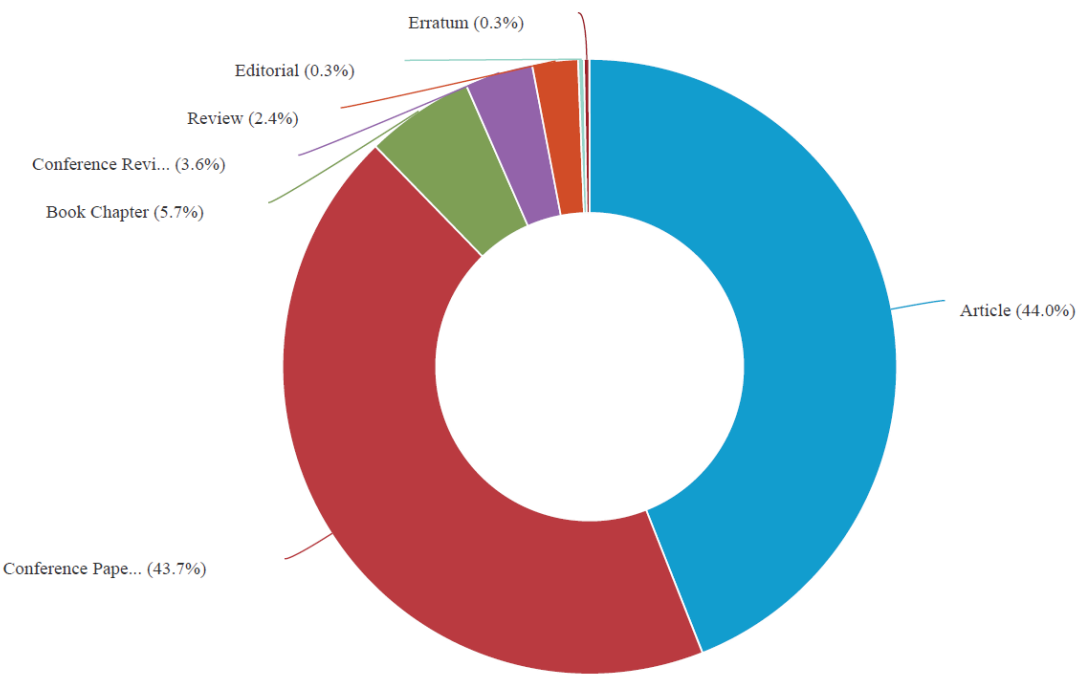

Copyright $\odot 2021$ Elsevier B.V. All rights reserved. Scopus $₫$ is a registered trademark of Elsevier B.V.

Figure 2. Search Results by Type

Source: Scopus 


\section{Literature Review}

After reviewing the blockchain and accounting literature, the first finding is that most of the articles are very technical, are written in the computer science area and the articles that try to connect $\mathrm{BCT}$ with accounting are struggling with inferences and possibilities rather than showing clear evidence and ways of using BCT in the accounting area. The studies in that area are at a very early stage and the answer to "how will blockchain affect accounting?" is up to the developmental stages in software programs connecting blockchain and accounting.

\section{Integration of Blockchain with Accounting Information Systems}

One of the most important studies that connect BCT with accounting belongs to Dai and Vasarhelyi (2017). They propose the use of blockchain as a medium for providing real-time, reliable, verifiable, and transparent accounting information to all related parties such as managers, auditors, creditors, and stakeholders. Real-time accounting and business monitoring can be provided with the integration of physical objects such as products, inventories, and production processes with the objects that have digital capabilities and have access to the Internet. Triple entry accounting, which has been suggested to increase the reliability and verifiability of the journal entries, can be realized with BCT because there is an opportunity to keep the entries in an independent and verifiable environment. BCT also enables managers to have "smart controls, which are computer programs that would operate on blockchain to automatically control business processes against pre-determined rules." Therefore, better control and assurance can be provided within a company with the third entries encoded into the blockchain (Dai and Vasarhelyi, 2017). According to Demirkan et al. (2020) and Kwilinski (2019), BCT may have a destructive effect on the double-entry accounting system, and a triple-entry accounting system may replace it. Currently, Request Network, Balanc3, Ledgerium and Pacio are examples of the accounting software programs that use a triple-entry accounting system (Cai, 2019).

Weigand et al. (2020) argue that DLT may have a major impact on the existing accounting information system shaped by internal participants, not only because of the immutability and traceability of records but also because it may provide an external consensus view. They claim that as a result of the spread of blockchain-based shared ledger technology, the focus of financial reporting will change from a business-centric to exchange-centric model, and this will greatly increase the quality and reliability of financial reporting.

Dai and Vasarhelyi (2017) try to explain the processes in accounting while using BCT with a simple purchase and sale transaction. When the purchaser records inventory and accounts payable in its ERP system (or in its regular accounting system), at the same time the transaction information is encoded to blockchain in the form of a digital token. Each account will have a corresponding blockchain account (like Bitcoin wallet) that contains an account's unique identifier, current balance, and cryptographical keys for verification. 
Bonsón and Bednárová (2019) name the blockchain environment of companies as the BCT ecosystem and divide it into two; the Company's BCT Ecosystem and Audit BCT ecosystem. In these systems, members operate as nodes. In the Company's BCT ecosystem, there are nodes for the company, suppliers, customers, banks, producers, investors, and the public administration and in the Audit BCT ecosystem, the nodes are public administration, auditors, and SEC. While creating an accounting information system in the blockchain ecosystem, the selection of nodes, the structure of the database, authorization, and verification protocols are very important aspects. After mentioning the design requirements, principles and features, Sogaard (2021) suggest governmental authorities use of BCT for the collection of value added tax receivables.

Blockchain is suggested as a management tool for supply chains by Dwivedi et al. (2020). High-value products or drugs need a more careful inquiry during the supply chain and blockchain may be a remedy for problems such as the tampering of products, delays, and fraud. They suggest using BCT with other technologies, especially with the Internet of Things, as an alternative to the ERP system. When all the supply chain activities are followed by the BCT, integrating the accounting systems with blockchain will be inevitable. Calderon and Stratopoulos (2020) show the implementation of BCT in a supply chain. They explain the whole process of initiating, validating and recording a transaction on $\mathrm{BCT}$ in one of the segments of Listerine.

The faithful financial information, which is "complete, neutral and free from errors" as mentioned in the Conceptual Framework of IASB, can be provided with the integration of BCT in a supply chain (McCallig et al., 2019). Bakarich et al. (2020) argue that integrating BCT into supply chain management will provide benefits in collecting true and verifiable information for sustainable reports, and so, companies wanting to adopt BCT, should seek ways to integrate $\mathrm{BCT}$ and also provide sustainable reporting procedures.

Based on an extensive literature review and from an organizational perspective, Tiron-Tudor et al. (2021) make a Strengths, Weaknesses, Opportunities and Threaths (SWOT) analysis of adopting BCT for accounting and auditing firms. Pimentel and Boulianne (2020) suggest the co-work and collaboration of academics and practitioners to have a better adoption processes. Roszkowska (2020) and Kwilinski (2019) claim that in the near future BCT may have a big role in accounting; many jobs such as billing, documenting, treating, registering bookkeeping, budgeting, and reconciliation might be done by autonomous programs based on BCT. These developments also have some implications for accounting and finance professionals; BCT may change job definitions and responsibilities (Church et al., 2020). Consequently, the content of accounting education should also conform to those new technologies and developments (Aldredge et al., 2020; Henage, 2020; Qasim and Kharbat, 2020). 


\section{Implications to Auditing}

Auditors need to collect relevant and reliable evidence to form an opinion. Auditors face many challenges while verifying whether the records are complete and accurate and evaluating the accuracy of the data gathered. The blockchain system architectures that are suggested for use by CPA firms or auditors create benefit in collecting high-quality evidence about the financial data of customers while saving their privacy. Changelog was supposed by Vincent et al. (2020) as a system architecture that will benefit CPA firms and auditors while keeping the customers' information secret.

With the increase of BCT and smart contracts, auditing and assurance services may change fundamentally and a blockchain ledger can be used as a source document by auditors in the auditing processes (Dai and Vasarhelyi, 2017). Rozario and Thomas (2019) extend the discussion of Dai and Vasarhelyi (2017) on the possible applications of blockchain and smart contracts to transform auditing and they suggest an external audit blockchain that can support smart audit procedures. Because the transactions entered into the blockchain by the acceptance of participating nodes, completeness, and accuracy checks are performed proactively, and blockchain attributes increase the integrity and reliability of the data. The information provided by IoT is also helpful in understanding the business risks of clients and the accuracy of auditors' estimates and valuations (Rozario and Thomas, 2019).

In the audit $\mathrm{BCT}$ ecosystem, cryptography can be used to design which node can see what information, so it can solve the privacy concerns of participants. Auditors can have continuous access to the ledgers of clients and so can make a continuous audit with BCT (Bonsón \& Bednárová, 2019). McCallig et al. (2019) propose a system that will enable the use of blockchain in a supply chain for "accounts receivable" only. If the suppliers and the buyer firm have the same blockchain system, auditors may also participate in the system and can see the receivable balances of suppliers and payable accounts of the purchaser. In order to preserve confidentiality, the system will not allow suppliers to see the balances of each other.

Industry 4.0 has been accepted as the reason for changes in the auditing profession and it has created new tools and new processes for the auditing profession. Audit 4.0 includes audit activities by using the data created by artificial intelligence, smart sensors, and the Internet of Things (Dai et al., 2019).

Big Four audit companies also have a big interest in BCT. The number of projects based on BCT, cloud computing, artificial intelligence, machine learning, and IoT has been increasing rapidly and KPMG's Spark Project is one of them. It is a cloud-based real-time accounting system that integrates artificial intelligence and machine learning (Henage, 2020). Church et al. (2020) claim that cloud computing has been evolving for BCT based accounting information systems. Deloitte offered Rubix, which is a blockchain-based software program that allows users to make smart contracts. KPMG developed its digital ledger services with 
Microsoft. EY works on Libra and Ops Chain for invoicing, pricing, digital contracts, and payments. EY also launched Crypto-Asset Accounting and Tax (CAAT) software to assist US firms to report their crypto-asset transaction when filing their tax returns and Tattoo to track wine. PWC launched De Novo as a tool to implement BCT in supply chains (Bonsón and Bednárová, 2019; Bonyuet, 2020; Kokina et al., 2017; Schmitz and Leoni, 2019; Zemánková, 2019; Y. Zhang et al., 2020).

\section{The Need for New Regulations and New Accounting Standards}

Blockchain has become popular with the increase in the demand for Bitcoin trade and it is used as a medium to record Bitcoin transactions (Bonsón and Bednárová, 2019; Bonyuet, 2020; Dai and Vasarhelyi, 2017). Bitcoin transactions have led to a new debate on how to account for digital money. While various definitions describe Bitcoin as "digital money" (Financial Action Task Force, 2014; Ron and Shamir, 2013) "what bitcoin exactly is" is still open to discussion. Is cryptocurrency money or an asset? Is it a product or an investment? The possible answers to those questions are debated in the related literature.

It is expected that the spread out of blockchain usage will lead to an increase in business transactions made with cryptocurrencies. However, the absence of legal regulations causes significant difficulties in accounting for cryptocurrency transactions (Sokolenko et al., 2019). Therefore, the need for an accounting standard on the subject is increasing day by day.

The main finding of the systematic literature review, conducted by Corbet et al. (2019), is that there are many gaps in the literature regarding cryptocurrency, such as; the potential benefits and uses of blockchain, evaluation of cryptocurrencies as part of a diversified portfolio, and legal, economic and regulatory issues. White et al., (2020) investigate whether the current regulations are applicable to cryptocurrencies. In that study, the behavior of bitcoin was examined with various methods, and it was found that Bitcoin mostly resembles a technology-based product. They concluded that current currency and security laws should not apply to cryptocurrencies.

Baur et al. (2018) research to analyze whether the Bitcoin is a medium of exchange or a (speculative) investment asset. Because one-third of Bitcoins are held by investors and a minority of users (both in number and Bitcoin balances) appear to use Bitcoin as a medium of exchange, they conclude that the main purpose of keeping Bitcoins is investing rather than using it as a medium of exchange. In addition to the classification of cryptocurrencies, their recognition and evaluation process are also uncertain. Morozova et al. (2020) state that there are four options for classifying cryptocurrencies according to the studies of specialists, professionals, and leading auditing firms: a) money, b) supply, c) financial asset, d) intangible asset. They also propose a prospective model for the valuation of crypto assets after initial recognition. Furthermore, the authors point out the need for a new IFRS standard for the accounting of crypto assets. 
According to the 17 characteristics mentioned in Ram's (2015) study, Pelucio-Grecco et al. (2020) investigate the asset classes that suit Bitcoin's characteristics best within the framework of IFRS. They report that 13 characteristics of bitcoin are compatible with currency, 10 are compatible with financial instruments, and 7 are compatible with intangible assets. Therefore, they suggest that the most suitable classification and most faithful representation of cryptocurrencies should be that of a foreign currency.

Procházka (2018) evaluates accounting models for cryptocurrencies under IFRS. The author identifies existing models that may be used for cryptocurrency transactions and then compares competing models that are possible for a certain type of transaction. According to the study, there are three points to be noted regarding the model that can be used in accounting for cryptocurrencies: (1) the business model, (2) the purpose of the transaction, and (3) the expected decision-usefulness of the model.

\section{The Challenges of Using Blockchain in Accounting}

Dai and Vasarhelyi (2017) classify the challenges of using BCT for accounting purposes under three categories: technological, organizational, and environmental. The stored data of Bitcoin transactions showed the need for larger storage systems if the data of other transactions are also kept in the blockchain systems. Would corporate blockchain streams quickly expand to an unmanageable size? What accounting data should be recorded in blockchain? and What other information (such as IoT data) should be loaded to blockchain in order to provide better assurance? are the important questions that should be answered in the technological context. Investing in new technologies, the need for training of managers, employees, and auditors, the requirement for new regulations, new accounting and auditing standards are supposed as other challenges of BCT (Dai \& Vasarhelyi, 2017).

The possibility of being stolen or loss of private keys of digital wallets, errors in smart contract codes, facing with a higher demand for auditing in a blockchain environment, higher computational power, storage capabilities, cybersecurity risk, litigation risk, the vulnerability of smart contracts, and regulatory acceptance of the use of blockchain are the risks of BCT that are mentioned by Rozario and Thomas (2019). O'Leary (2019) points out the lack of generalizability issues related to BCT.

Users of BCT should be aware that without the effective controls of IT infrastructure, the data provided by blockchain may not be reliable (Sheldon, 2019). P. Zhang and Zhou (2020) stress the importance of designing new consensus mechanisms to improve the security and trust of BCT. The increasing use of BCT may create a huge demand for employees who know about blockchain and other new technologies that have started being used in the accounting area. Therefore, the transformation of accounting education is also a challenge and necessity all over the world (Y. Zhang et al., 2020). Stratopoulos (2020) suggest the combination of storytelling and scaffolding approach to teach BCT to accounting students. 
Abdennadher et al. (2021) made interviews with accountants and auditors in order to understand possible benefits and challenges of using BCT in accounting and auditing: difficulty in correcting mistakes, information overload, the need for new assurance services and stronger internal audit are challenges that have been mentioned by accountants and auditors.

\section{Critical Views on the Integration of Blockchain and Accounting}

One important study that focuses on the necessity of blockchain belongs to Alles and Gray (2020). They criticize the marketing efforts of big audit firms and say that "the Big-4 aim to persuade clients to hire them to develop blockchain implementations. However, they fail to answer, "What is the problem for which blockchain is the solution?". Additionally, they point out the "first-mile problem" which is the problem related to the reliability of the data entered into the blockchain system if it is related to the real-life events other than cryptocurrency transfers. Adapting IoT may increase the reliability of the data, however when the parties in the blockchain enter the data, the correctness of the data will always be questioned.

Rîndaşu (2019) tries to answer the following question in her study: "Is blockchain usage in accounting an innovation or is just another well-advertised technology that will not bring any kind of relevant benefits?'. She thinks that the BCT may be beneficial for only some companies, and before adopting it, companies should have a well-designed decision-making process. Bakarich et al. (2020) points out the necessity of assessing internal and external costs and benefits of BCT, otherwise companies will not be eager to invest money, time and human capital.

Maffei et al. (2020) differentiates their literature review by focusing more on risks and threats of adopting BCT in accounting and auditing practices. They point out the following risks of implementing BCT: underestimating the possible manipulative and fraudulent practices, underestimating the threats of wrong classification and valuation of accounts, lack of expertise while evaluating the business performance, and the risks created by unexperienced IT personnel while adopting and operationalizing BCT.

\section{Conclusion}

Information technologies are developing very rapidly, and accounting information technologies are following those developments and changes very closely. BCT and cryptocurrencies are two of the current discussion topics in the accounting world. Although it has a history of about ten years, the market cap of crypto coins is nearly $\$ 1.4$ trillion. Moreover, the number of companies that accept payments with cryptocurrencies, the number of crypto money ATMs, and the number of users using cryptocurrency as a medium of exchange are increasing day by day. 
Blockchain was a medium used to exchange Bitcoin at the beginning, however, different areas that the blockchain can provide benefit to have also been discovered. The finance sector is affected by those developments most. Researchers from different study areas started to conduct research projects on BCT. Accounting is also one of the areas that are expected to be affected by BCT. Accounting academics, accounting journals, and accounting firms have an increasing interest in those new technologies in order not to stay behind those fast developments.

In order to foresee the potential effects of BCT on accounting, a systematic literature review was conducted in the current study. The articles found as the result of database searches are written mainly in the areas of computer science and accounting information systems. Articles in the computer journals focused on the development of BCT and how it can be modified to be more useful in some selected areas. On the other hand, articles that try to connect BCT and accounting have very optimistic assumptions about the usage of BCT in accounting and most of them have the expectation of an accounting system fully based on BCT.

The clear point is that, with the increase in the transactions made by using Bitcoin and other cryptocurrencies, there will be an increasing demand to use BCT. However, the replacement of the current software programs with Blockchain is up to the developments in BTC and the elimination of its drawbacks. High costs, the need for hiring new personnel, difficulty in keeping the security of private information, new business risks, and a lack of regulations and standards are the main obstacles to the spread of BCT.

The contribution of this study is mainly to accounting regulators, professionals, and academics who want to follow the developments in BCT and its potential effects on accounting information systems. The study may help them to adapt to the changes more easily and foresee the potential risks and opportunities. Accordingly, necessary regulations can be made, new standards can be released, and the necessary education can be given to accounting professionals and accounting students.

Lastly, we want to make some suggestions for further research. Conducting case studies to examine the adoption and usage of BCT in accounting and auditing environment will be very valuable. Searching the improvements in usage and adoption of BCT in accounting, internal control and auditing in a particular country setting, such as Turkey, conducting cross country studies and comparative studies between different industries will add much value to the current literature.

Peer-review: Externally peer-reviewed.

Conflict of Interest: The authors have no conflict of interest to declare.

Grant Support: The authors declared that this study has received no financial support.

Author Contributions: Conception/Design of study: A.A., G.S.K.; Data Acquisition: A.A., G.S.K.; Data Analysis/Interpretation: A.A., G.S.K.; Drafting Manuscript: A.A., G.S.K.; Critical Revision of Manuscript: A.A., G.S.K.; Final Approval and Accountability: A.A., G.S.K. 


\section{References}

Abdennadher, S., Grassa, R., Abdulla, H. \& Alfalasi, A. (2021). The effects of blockchain technology on the accounting and assurance profession in the UAE: an exploratory study. Journal of Financial Reporting and Accounting. ahead-of-p(ahead-of-print). https://doi.org/10.1108/JFRA-05-2020-0151

Aldredge, M., Rogers, C., \& Smith, J. (2020). The strategic transformation of accounting into a learned profession. Industry and Higher Education, ahead-of-p. https://doi.org/10.1177/0950422220954319

Ali, O., Ally, M., Clutterbuck, \& Dwivedi, Y. (2020). The state of play of blockchain technology in the financial services sector: A systematic literature review. International Journal of Information Management, 54 , 102199. https://doi.org/https://doi.org/10.1016/j.ijinfomgt.2020.102199

Alles, M., \& Gray, G. L. (2020). "The first mile problem": Deriving an endogenous demand for auditing in blockchain-based business processes. International Journal of Accounting Information Systems, 38(100465). https://doi.org/https://doi.org/10.1016/j.accinf.2020.100465

Asmundson, I., \& Oner, C. (2012). Back to Basics-What Is Money? Finance \& Development, 49(3), $52-53$. https:/www.bookstore.imf.org/books/title/finance-development-subscription?code=f\&d

Back, A., Corallo, M., \& Dashjr, L. (2014). Enabling blockchain innovations with pegged sidechains. https:// blockstream.com/sidechains.pdf

Bakarich, K.M., Castonguay, J. \& O'Brien, P.E. (2020). The Use of Blockchains to Enhance Sustainability Reporting and Assurance. Accounting Perspectives, 19 (4), 389-412. https://doi.org/10.1111/19113838.12241

Bamakan, S. M. H., Motavali, A., \& Bondarti, A. B. (2020). A survey of blockchain consensus algorithms performance evaluation criteria. Expert Systems with Applications, 154(113385). https://doi.org/10.1016/j. eswa.2020.113385

Baur, D. G., Hong, K., \& Lee, A. D. (2018). Bitcoin: Medium of exchange or speculative assets? Journal of International Financial Markets, Institutions and Money, 54, 177-189. https://doi.org/10.1016/j.intfin.2017.12.004

Bonsón, E., \& Bednárová, M. (2019). Blockchain and its implications for accounting and auditing. Meditari Accountancy Research, 27(5), 725-740. https://doi.org/10.1108/MEDAR-11-2018-0406

Bonyuet, D. (2020). Overview and impact of blockchain on auditing. International Journal of Digital Accounting Research, 20,31-43. https://doi.org/10.4192/1577-8517-v20_2

Boucher, P., Nascimento, S., \& Kritikos, M. (2017). How Blockchain Technology Could Change Our Lives. European Parliament, 4-25. https://doi.org/10.2861/926645

Cai, C. W. (2019). Triple-entry accounting with blockchain: How far have we come? Accounting \& Finance. https://doi.org/10.1111/acfi.12556

Calderon, J. and Stratopoulos, T. C. (2020). What Accountants Need to Know about Blockchain. Accounting Perspectives, 40 (3), 303-323.

Central Bank of the Republic of Turkey. (2018). Kâğıt Paranın Tarihçesi. https:/www.tcmb.gov.tr/wps/wcm/ connect/d189b219-fe71-40bf-9754-6a5f7d0a65eb/KagitParaTarihce.pdf?MOD=AJPERES\&CVID=

Chang, V., Baudier, P., Zhang, H., Xu, Q., Zhang, J., \& Arami, M. (2020). How Blockchain can impact financial services - The overview, challenges and recommendations from expert interviewees. Technological Forecasting and Social Change, 158(120166). https://doi.org/10.1016/j.techfore.2020.120166

Church, K. S., Schmidt, P. J., \& Ajayi, K. (2020). Forecast Cloudy-Fair or Stormy Weather: Cloud Computing Insights and Issues. Journal of Information Systems, 34(2), 23-46. https://doi.org/10.2308/isys$18-037$ 
Corbet, S., Lucey, B., Urquhart, A., \& Yarovaya, L. (2019). Cryptocurrencies as a financial asset: A systematic analysis. International Review of Financial Analysis, 62, 182-199. https://doi.org/10.1016/j. irfa.2018.09.003

Dai, J., He, N., \& Yu, H. (2019). Utilizing Blockchain and Smart Contracts to Enable Audit 4.0: From the Perspective of Accountability Audit of Air Pollution Control in China. Journal of Emerging Technologies in Accounting, 16(2), 23-41. https://doi.org/10.2308/jeta-52482

Dai, J., \& Vasarhelyi, M. A. (2017). Toward blockchain-based accounting and assurance. Journal of Information Systems, 31(3), 5-21. https://doi.org/10.2308/isys-51804

Demirkan, S., Demirkan, I., \& McKee, A. (2020). Blockchain technology in the future of business cyber security and accounting. Journal of Management Analytics, 7(2), 189-208. https://doi.org/10.1080/2327 0012.2020 .1731721

Denyer, D., \& Tranfield, D. (2009). Producing a systematic review. In D. A. Buchanan \& A. Bryman (Eds.), The SAGE handbook of organizational research methods. In The Sage handbook of organizational research methods (pp. 671-689). https:/www.cebma.org/wp-content/uploads/Denyer-Tranfield-Producing-aSystematic-Review.pdf

Dwivedi, S. K., Amin, R., \& Vollala, S. (2020). Blockchain based secured information sharing protocol in supply chain management system with key distribution mechanism. Journal of Information Security and Applications, 54(102554). https://doi.org/10.1016/j.jisa.2020.102554

European Banking Authority. (2014). EBA Opinion on virtual currencies (Issue EBA/Op/2014/08).

European Central Bank. (2012). Virtual currency schemes. European Central Bank-Eurosystem.

European Central Bank. (2015). Virtual currency schemes - a further analysis. European Central BankEurosystem. https://doi.org/10.2866/662172

European Central Bank, \& Bank of Japan. (2018). Stella: BOJ / ECB joint research project on DLT.

Financial Action Task Force. (2014). Virtual Currencies Key Definitions and Potential AML / CFT Risks (Issue June). www.fatf-gafi.org

Grant, M. J., \& Booth, A. (2009). A typology of reviews: An analysis of 14 review types and associated methodologies. Health Information and Libraries Journal, 26(2), 91-108. https://doi.org/10.1111/j.14711842.2009.00848.x

Henage, R. (2020). KPMG Spark: Bringing cutting-edge technology to SME clients. Academy of Accounting and Financial Studies Journal, 24(3).

Innes, A. M. (1913). What is Money? The Banking Law Journal, 30(5), 377-408.

Investing.com. (2021). https://www.investing.com/crypto/currencies. Retrieved on 26.06.2021.

Jesson, K. J., Matheson, L., \& Lacey, M. F. (2011). Doing your Literature Review. In Sage Publications Ltd.

Keynes, J. M. (1915). The Island of Stone Money. The Economic Journal, 25(98), 281-283. https://doi. org $/ 10.2307 / 2222196$

Kokina, J., Mancha, R., \& Pachamanova, D. (2017). Blockchain: Emergent Industry Adoption and Implications for Accounting. Journal of Emerging Technologies in Accounting, 14(2), 91-100. https://doi. org/10.2308/jeta-51911

Kornfeld, T., Guagliardo, J., \& Nowak, G. J. (2016). Expert $Q \&$ A on Blockchain Technology in Banking and Financial Services. Thomson Routers Practical Law. https://content.next.westlaw.com/Document/I78075f1f490211e698dc8b09b4f043e0/View/FullText.html?contextData=(sc.Default)\&transitionType=Default 
Kwilinski, A. (2019). Implementation of blockchain technology in accounting sphere. Academy of Accounting and Financial Studies Journal, 23(Special Isue 2).

Lafourcade, P., \& Lombard-Platet, M. (2020). About blockchain interoperability. Information Processing Letters, 161(105976). https://doi.org/10.1016/j.ipl.2020.105976

Maesa, D. F. D., \& Mori, P. (2020). Blockchain 3.0 applications survey. Journal of Parallel and Distributed Computing, 138, 99-114. https://doi.org/10.1016/j.jpdc.2019.12.019

Maffei, M., Casciello, R. and Meucci, F. (2021), "Blockchain technology: uninvestigated issues emerging from an integrated view within accounting and auditing practices", Journal of Organizational Change Management, 34 (2), 462-476.

McCallig, J., Robb, A., \& Rohde, F. (2019). Establishing the representational faithfulness of financial accounting information using multiparty security, network analysis and a blockchain. International Journal of Accounting Information Systems, 33, 47-58. https://doi.org/10.1016/j.accinf.2019.03.004

Mills, D., Wang, K., Malone, B., Ravi, A., Marquardt, J., Chen, C., Badev, A., Brezinski, T., Fahy, L., Liao, K., Kargenian, V., Ellithorpe, M., Ng, W., \& Baird, M. (2017). Distributed ledger technology in payments, clearing and settlement. Journal of Financial Market Infrastructures, 6(2/3), 207-249. https://doi. org/10.21314/JFMI.2018.095

Morozova, T., Akhmadeev, R., Lehoux, L., Yumashev, A., Meshkova, G., \& Lukiyanova, M. (2020). Crypto asset assessment models in financial reporting content typologies. Entrepreneurship and Sustainability Issues, 7(3), 2196-2212. https://doi.org/10.9770/jesi.2020.7.3(49)

Nakamoto, S. (2008). Bitcoin: A Peer-to-Peer Electronic Cash System. https://bitcoin.org/bitcoin.pdf

O'Leary, D. E. (2019). Some issues in blockchain for accounting and the supply chain, with an application of distributed databases to virtual organizations. Intelligent Systems in Accounting, Finance and Management, 26(3), 137-149. https://doi.org/10.1002/isaf.1457

Official Newspaper, (16.04.2021), https://www.resmigazete.gov.tr/eskiler/2021/04/20210416-4.htm), Retrieved on 26.06.2021.

Pelucio-Grecco, M. C., Santos Neto, J. P. dos, \& Constancio, D. (2020). Accounting for bitcoins in light of IFRS and tax aspects. Revista Contabilidade \& Finanças, 31(83), 275-282. https://doi.org/10.1590/1808057x201909110

Pimentel, E. and Boulianne, E. (2020). Blockchain in Accounting Research and Practice: Current Trends and Future Opportunities. Accounting Perspectives. 19 (4), 325-361.

Procházka, D. (2018). Accounting for Bitcoin and Other Cryptocurrencies under IFRS: A Comparison and Assessment of Competing Models. The International Journal of Digital Accounting Research, 18, 161188. https://doi.org/10.4192/1577-8517-v18_7

Qasim, A., \& Kharbat, F. F. (2020). Blockchain Technology, Business Data Analytics, and Artificial Intelligence: Use in the Accounting Profession and Ideas for Inclusion into the Accounting Curriculum. Journal of Emerging Technologies in Accounting, 17(1), 107-117. https://doi.org/10.2308/jeta-52649

Ram, A. J. (2015). Accounting for the Bitcoin: An initial perspective [University of the Witwatersrand]. http://wiredspace.wits.ac.za/bitstream/handle/10539/20186/Accounting for the Bitcoin - An Initial Perspective by Asheer J. Ram.pdf?sequence=1

Rashideh, W. (2020). Blockchain technology framework: Current and future perspectives for the tourism industry. Tourism Management, 80(104125). https://doi.org/10.1016/j.tourman.2020.104125

Rîndaşu, S.-M. (2019). Blockchain in accounting: Trick or treat? Information Security Management, 20 (170), 143-147. 
Ron, D., \& Shamir, A. (2013). Quantitative Analysis of the Full Bitcoin Transaction Graph. In A.-R. Sadeghi (Ed.), Financial Cryptography and Data Security 17th International Conference, FC 2013 (pp. 6-22).

Roszkowska, P. (2020). Fintech in financial reporting and audit for fraud prevention and safeguarding equity investments. Journal of Accounting \& Organizational Change, ahead-of-p(ahead-of-print). https://doi. org/10.1108/JAOC-09-2019-0098

Rozario, A. M., \& Thomas, C. (2019). Reengineering the Audit with Blockchain and Smart Contracts. Journal of Emerging Technologies in Accounting, 16(1), 21-35. https://doi.org/10.2308/jeta-52432

Salimitari, M., Chatterjee, M., \& Fallah, Y. P. (2020). A survey on consensus methods in blockchain for resource-constrained IoT networks. Internet of Things, 11, 100212. https://doi.org/10.1016/j.iot.2020.100212

Schmitz, J., \& Leoni, G. (2019). Accounting and Auditing at the Time of Blockchain Technology: A Research Agenda. Australian Accounting Review, 29(2), 331-342. https://doi.org/10.1111/auar.12286

Sheldon, M. D. (2019). A Primer for Information Technology General Control Considerations on a Private and Permissioned Blockchain Audit. Current Issues in Auditing, 13(1), A15-A29. https://doi.org/10.2308/ ciia-52356

Sogaard, J. S. (2021). A blockchain-enabled platform for VAT settlement. International Journal of Accounting Information Systems, 40, https://doi.org/10.1016/j.accinf.2021.100502.

Sokolenko, L., Ostapenko, T., Kubetska, O., Portna, O., \& Tran, T. (2019). Cryptocurrency: Economic essence and features of accounting. Academy of Accounting and Financial Studies Journal, 23(Special Is 2), 1-6. https://www.scopus.com

Stratopoulos, T. C. (2020). Teaching Blockchain to Accounting Students. Journal of Emerging Technologies in Accounting. 17 (2), 63-74.

Swanson, T. (2015). Consensus-as-a-service: a brief report on the emergence of permissioned, distributed ledger systems. In Creative Commons Attribution.

Tiron-Tudor, A., Deliu, D., Farcane, N. \& Dontu, A. (2020). Managing change with and through blockchain in accountancy organizations: a systematic literature review. Journal of Organizational Change Management, 34 (2), 477-506.

Vincent, N. E., Skjellum, A., \& Medury, S. (2020). Blockchain architecture: A design that helps CPA firms leverage the technology. International Journal of Accounting Information Systems, 38. https://doi. org/10.1016/j.accinf.2020.100466

Walport, M. (2015). Distributed ledger technology: Beyond block chain. In Government Office for Science.

Wang, X., Yu, G., Zha, X., Ni, W., Liu, R. P., Guo, Y. J., Zheng, K., \& Niu, X. (2019). Capacity of blockchain based Internet-of-Things: Testbed and analysis. Internet of Things, 8(100109). https://doi.org/10.1016/j. iot.2019.100109

Wang, Y., \& Kogan, A. (2018). Designing confidentiality-preserving Blockchain-based transaction processing systems. International Journal of Accounting Information Systems, 30, 1-18. https://doi. org/10.1016/j.accinf.2018.06.001

Weigand, H., Blums, I., \& Kruijff, J. de. (2020). Shared Ledger Accounting — Implementing the Economic Exchange pattern. Information Systems, 90(101437). https://doi.org/10.1016/j.is.2019.101437

White, R., Marinakis, Y., Islam, N., \& Walsh, S. (2020). Is Bitcoin a currency, a technology-based product, or something else? Technological Forecasting and Social Change, 151(119877). https://doi.org/10.1016/j. techfore.2019.119877

Yermack, D. (2013). Is Bitcoin a real currency? An economic appraisal. In NBER WORKING PAPER SERIES (Vol. 53, Issue 9). 
Yıldırım, M. (2019). Blok Zincir Teknolojisi, Kripto Paralar ve Ülkelerin Kripto Paralara Yaklaşımları. Bartın Üniversitesi İktisadi ve İdari Bilimler Fakültesi Dergisi, 10 (20), 265-277.

Yu, G., Zha, X., Wang, X., Ni, W., Yu, K., Zhang, J. A., \& Liu, R. P. (2020). A Unified Analytical model for proof-of-X schemes. Computers and Security, 96 (101934). https://doi.org/10.1016/j.cose.2020.101934

Zemánková, A. (2019). Artificial intelligence and blockchain in audit and accounting: Literature review. WSEAS Transactions on Business and Economics, 16, 568-581.

Zhang, P., \& Zhou, M. (2020). Security and Trust in Blockchains: Architecture, Key Technologies, and Open Issues. IEEE Transactions on Computational Social Systems, 7(3), 790-801. https://doi.org/10.1109/ TCSS.2020.2990103

Zhang, Y., Xiong, F., Xie, Y., Fan, X., \& Gu, H. (2020). The Impact of Artificial Intelligence and Blockchain on the Accounting Profession. IEEE Access, 8, 110461-110477. https://doi.org/10.1109/ACCESS.2020.3000505 
